\title{
Review on Brand Citizenship Behavior and Importance of Employees in Brand Strategy
}

\author{
A. P. Medis ${ }^{1 *}$ \\ ${ }^{1}$ Department of Marketing, University of Kelaniya, Sri Lanka \\ *Corresponding Author: medis@kln.ac.lk
}

\begin{abstract}
The connection of internal marketing including employees for a brand is a critically reviewed notion in marketing studies. The concept of brand citizenship behavior is one of the most researched concepts connected to brand strategies whereas importance of employees within the domain of branding is treated as a significant matter. However, empirical studies still claim to investigate the BCB with reference to different product contexts and markets to examine how it results brand related outcomes. Meanwhile, many studies attempt to investigate the concept of BCB in line with different brand related behaviors of customers and staff. Alongside, this paper examines the empirical evidence on $\mathrm{BCB}$ in relation to connected concepts and variables whilst specific attention is made for service sector. Paper presents the literature review explaining how BCB interlocks with some significant notions including brand knowledge. It followed a literature review as the main research tool and author used prominent journal articles as the main source to collect empirical evidence. Paper concludes the importance of $\mathrm{BCB}$ for the future research directions followed by a discussion highlighting how BCB and related concepts had been examined in previously held studies.
\end{abstract}

Keywords: Brand Citizenship Behavior, Brand Knowledge, Brand Strategy, Employees.

\section{INTRODUCTION}

Brand building has been a vital focus in many organizations as it directly contributes to the corporate and its performance, including financial and non-financial perspectives (Aaker, 1996). Most of the studies discuss the brand building strategy connected to brand equity and brand relationships behaviors. There are theoretical arguments claiming that brand strategies need to be specific as per the product forms like services and consumer goods (Burmann \& Zeplin, 2005; Dissanayake, Ismail \& Phalven Sharif , 2017). Brand Citizenship Behavior (BCB) is relatively a new concept that explains how employees could improve their delivery performance by aligning their attitude and their behavior to the organization's brand. In essence, behavior of brand citizenship refers to the voluntary nature of the workers to project a series of behavior generic employees that enhances the identity of brand (Burmann \& Zeplin, 2005). Brand citizenship behavior was basically introduced by German scholars and it has been evolved from the theory of organization citizenship behavior (OCB) (Burmann \& Zeplin, 2005). Behavior of workers in building brand has gained attention from scholars of Western countries (Burmann \& Zeplin, 2005; Burmann et al., 2009; King \& Grace 2008; Punjaisri \& Wilson, 2007). However, scant of evidence prevails to understand what exactly is expected from the employees when representing the brand and what is really meant by the conduct of employee characteristics that improve the performance of the brand (Baumgarth \& Schmidt, 2009).

Meanwhile, the significance of internal branding has been reviewed in many literatures claiming how important internal branding to sustain the product branding and corporate 
branding strategies. In this scenario, the importance of people or staff of an organization should be seriously considered as a branding tool (Kimpakorn \& Tocquer, 2009). There are different concepts and models explaining how branding could connect to the internal business environment. One of the prominent concepts that explains how employees are integrated to brand is brand citizenship behavior. Brand citizenship behavior could be identified as the way how employees are attributed by the features, behaviors and engagement with the value proposition positioned with a product brand or corporate brand (Baumgarth \& Schmidt, 2009). Accordingly, studies explain and argue $\mathrm{BCB}$ needs to be properly established if a brand needs to deliver what it promises. Meanwhile, some studies argue services sector needs a serious attention on BCB as it largely connects with the employees as a mean of value transformation to consumers. The branding related concepts that connect with the employees and culture of the organization like brand love, brand engagement, employee brand knowledge and brand commitment have been explained with the concept of $\mathrm{BCB}$ (Baumgarth \& Schmidt, 2009; Nirmali et al., 2018). However, empirical arguments are found claiming BCM has to be further tested with different sectors to configure how well BCB explains the way employees could commit to the brand promise (Burmann and Zeplin, 2005; Nirmali et al., 2018).

Thus, the need of further investigating the empirical evidences on $\mathrm{BCB}$ with different concepts and applications is a valid contribution to present knowledge. Alongside, this paper attempts to conduct a conceptual review on $\mathrm{BCB}$ connecting its core with the related variables and concepts. Paper contributes to discuss how to extend future research works alongside the BCB to contribute more empirical insights to exciting knowledge and practice perspectives (Nirmali et. al. 2018).

\section{PURPOSE AND METHODOLOGY}

As per the brief background rationale presented in the paper, it mainly focuses to contribute an empirical review on the main domain of $\mathrm{BCB}$ by highlighting how the related components have been researched with associated to concepts and variables. Additionally, paper contributes future research directions to examine the role of employees in internal branding and brand related behaviors of employees towards the overall brand strategy. It has briefed how organizations use the employee-related practices to develop branding strategy with reference to different sectors including services as a significant context. Alongside, this study has followed a deductive approach and executed a comprehensive literature review as the main research tool. Author conducted the literature review on journal articles and attempted to highlight some managerial implications to add how the review could direct industry practices.

\section{THEORETICAL REVIEW ON BRAND CITIZENSHIP BEHAVIOR}

$\mathrm{BCB}$ has been found with different contents as per the empirical investigations are found. Alongside, brand-consistent behavior is commonly discussed based on two major streams, namely in-role brand behavior and extra-role brand behavior. For instance, Kimpakorn and Tocquer (2009), King and Grace (2008) and Punjaisri and Wilson (2007) highlighted brand-consistent behavior as more toward in-role brand behavior while Morhart, Herzog and Tomczak (2009) and Burmann et al. (2009) stated that brand-consistent behavior is best described as extra-role brand behavior. However, there is no consistent terminology used for both concepts of brand-consistent behavior. Another major issue concerned with this concept (in-role and extra role brand behavior) is, regarding un-dimensional versus multidimensional of employees' brandconsistent behavior. Therefore, the study at hand will examine whether such employees' brand-consistent behavior is un-dimensional or best explained by multidimensional concept. In essence, in-role brand behavior is related to 
the ability of employees to deliver the brand promise. As per Morhart et al. (2009), in-role brand behavior is meeting prescribed brand roles while Burmann et al. (2009) termed this as brand compliance. In-role brand behavior would be easily fulfilled by most organization. Extra-role brand behavior refers to employees' willingness to take extra miles on behalf of the organization's brand. This connects with job, task or behavior that goes beyond formal prescribed brand roles such as positive word of mouth, participation, helping behavior, sportsmanship, brand enthusiasm and other employees' extra brand effort (Burmann et al., 2009; Morhart et al., 2009). Based on the assumption that organization sustained their brand competitive advantage through differentiation strategy, thus, extra-role brand behavior would be the best practice for brand differentiation. This is because, to engage employees with extra-role brand behavior that goes beyond their formal brand role is not easily found in every organization/ brand. In addition, Burmann et al. (2009) suggested that extra-role brand behavior is more superior to in-role brand behavior in stimulating favorable brand identity. As such, extra-role brand behavior will be examined in this study which is conceptualized as brand citizenship behavior.

$\mathrm{BCB}$ is a relatively new concept that explains how employees could improve their brand delivery performance by aligning their attitude and behavior to the organization's brand. BCB was originated from organizational citizenship behavior that acknowledged the internal micro-level performance (i.e. employee's brand performance) to external target groups rather than macro-level performance (i.e. job and organizational performance) alone. According to Burmann et. al. (2009), BCB is built up by seven constructs which is believed to represent the brand-related behavior of employees to enhance the organization's brand success and later sustain the organization's competitive advantages. The constructs are as follows:

- Helping Behavior. Helping behavior is associated with positive attitude, friendliness, helpfulness, and empathy towards internal and external customer, taking responsibility for tasks outside of their town area if necessary such as following up on complaints.

- Sportsmanship. Sportsmanship is associated with no complaining, even if engagement for the brand cause inconvenience; willingness to engage for the brand even at the opportunity cost.

- Brand Endorsement. Brand endorsement entails to employee's recommendation of the brand to others also in non-job-related situations for example, to friends; passing on the brand identity to newcomers in the firm.

- Brand Enthusiasm. Brand enthusiasm highlights how employee's ability is there to show extra initiative while engaging in brand-related behavior.

- Brand Consideration. Brand consideration indicates how employee's adherence relates to brand-related behavior guidelines and reflection of brand impact before communicating or taking action in any condition.

- Self-development. Self-development has been mentioned as employee's willingness to continuously enhance brand-related skills and competencies.

- Brand-advancement. Brand advancement communicates how employee's contribution connects to the adaptation of the brand identity concept to changing market needs or new organizational competencies, such as through passing on customer feedback or generating innovative thoughts.

In brief, the constructs cover employees' consideration towards the brand that goes beyond their formal prescribed job mainly to deliver the brand promise in appropriate manner. Thus, based on the comprehensiveness of the brand behavior construct proposed by Burmann and Zeplin (2005), brand citizenship behavior will be adapted because it provides a more holistic view of brand performance in the context of employees as opposed to other's works. 
However, the research findings of Burmann et al. (2009) revealed that only three out of seven constructs (namely helping behavior, brand enthusiasm and brand development) significantly explained brand citizenship behavior. As such, there is the need to test the construct with the new data set mainly to increase the superiority of the construct.

Most of business organizations are seriously focused on the brand management from perception of customers which directed to understand customers' behaviour towards the brand. According to Keller (2010), one of the most cited literatures in brand equity that led to 'Customer-Based Brand Equity' (CBBE) theory which concerned on how customers' behaviour contributed to a long term brand survival challenging business environment in order to sustain the brand's competitive advantage. Additionally, companies should have to maintain a balance standpoint in brand management which highlights both external and internal brand management. This is happening because the workers of the company which represent the brand have an opportunity to develop the image of the brand and the status as well as performance of the brand through the behaviour and the attitude of them, mostly when they are delivering the service (Burmann et al., 2005). Hence, the management should recognise and inspire the employees' work that could improve the complete brand routine.

According to the views of De Chernatony and Cottam (2009), workers are known as the brand delivery. Thus, in order to deliver the promise of the brand, employees should equally improve their behaviour and attitude according to the value of the brand (Ind, 2001) by 'living the brand'. Knowledge of how employees could improve the performance of the brand somewhat limited in Sri Lankan perspective (Punjaisri \& Wilson, 2007). Thus, this is happening because a lot of studies have been engaged to understand the customer's behaviour better that led to the improvements of the 'customer-based brand equity' (Keller, 2010).
Therefore, it is clear that behavior of employees those who contribute to the success of the brand had been ignored by scholars and practitioners, and the current attempts to study about understanding on how obstinately focus on the urgencies of the employees to repeatedly keep up the equality between the behavior and the attitude towards the value of the brand by 'living the brand'. Presently, except Burmann and Zeplin (2005) and Burmann, Zeplin and Riley (2009), there are no disagreements of what is expected by the employees of the bank's 'brand behavior that 'live the brand'. In this regards, Burmann and Zeplin (2005) had been recognized seven leading employers behaviors that are proportionate with living the brand which is named as 'brand citizenship behavior' (BCB). The behaviors contain helping behavior, selfdevelopment, brand enthusiasm, brand consideration, sportsmanship, brand advancement and brand endorsement. Nonetheless, results of the research done by Burmann et al. (2005) found out that 'brand citizenship behavior' is built by three main dimensions called; brand enthusiasm, helping behavior and brand development. Therefore, the authors recommended that the $\mathrm{BCB}$ measuring should be tested in other situations and nations to increase the construction's advantages.

The concept is still opened to be researched. It is still recommended that without enough brand-related knowledge, workers of the company are unable to understand what is needed to deliver the brand promise and live up the brand. As discussed, it is significant to understand how the workers' education about the brand effect their behavior specially BCB (Jayampathi \& Dissanayake, 2018). Literature review shows a mixed result in relation to relationship between workers' education about the brand on employees' brand citizenship behavior. According to research findings of the King \& Grace (2008), brand knowledge affected the employees' brand role in this regard and how they are willing to engage in brand supportive behavior. But Kimpakorn and Tocquer (2009), have failed to found much 
support on brand knowledge and how it influences employees brand commitment and other behavior required for brand support. Furthermore, according to assumptions of Burmann et al. (2009) brand knowledge works as mediating variable but not as key determinants of employees BCB. Evidently, employees especially in the service industry implicitly project the brand identity to consumers (Kimpakorn \& Tocquer, 2010).

\section{DISCUSSION ON BRAND CITIZENSHIP BEHAVIOR: KNOWLEDGE AND PRACTICE PERSPECTIVES}

As it mentioned in the literature review, BCB could be investigated with different concepts that connects to internal branding perspectives. This paper highlights that $\mathrm{BCB}$ interrelates with employees' behavior attributed with other brand related aspects. For instance, it can conclude that the relationship between $\mathrm{BCB}$ and brand knowledge of employees is a significant research proposition to be examined in different industries. Knowledge of employee brand is the sense of how to make employees acquire organizational knowledge to help them carry out their roles and responsibilities in accordance with the brand promise (King \& Grace, 2008). In general, training and internal communication are the key sources of how to make employees understand their work and their organization (Ellickson, 2002; King \& Grace, 2008; Punjaisri et al., 2009; Thomson et al., 1999). The most relevant information and training received by employees, the competition more than they are in the achievement of objectives of general organization (Buckley \& Caple, 1995). Therefore, in connection with the performance of the brand, is also postulated that more knowledge and understanding employees have towards your organization's brand, more competition is in the delivery of the brand promise and increase willingness to participate in the brand citizenship behavior.

Studies of Burmann et al. (2008), Kimpakorn and Dimmit (2007), Morhart, Herzog and Tomczak (2009) and Solnet (2006) noted that leadership is an important factor in influencing behavior used brand - consistent behavior. In addition, mixed results have been reported on the relationship between knowledge of brand and brand consistent behaviour. For example, the recent discovery of Kimpakorn and Lyon (2009) revealed that knowledge of brand of factory's employees influences insignificantly on employees brand commitment and in last instance of brand support behavior.

According to Burmann and Zeplin (2005) the urgency of leadership is important in stimulating employees' brand commitment and behavior. The conceptual papers concerning behavioral approach to internal brand management identified brand leadership at two main level namely; macro level (include executive board and Chief Executive Officer) and micro level (executive). Their finding revealed that leaders at all level (i.e. macro and micro level) need to support internal branding by words and actions and became the role model for the brand (Burmann \& Zeplin, 2005). The scholars also came to conclusion that transformational leadership approach is the best in enticing employees' BCBs. Yet, there is no empirical evidence to support the argument. This notion is derived based on the researcher's overview of how different type of leadership practices had influence employees' OCB.

Recent findings of Burmann et al. (2009) also did not systematically check the influence of different type of leadership practices (namely transformational and transactional leadership) on employees' brand commitment and BCBs. The study indicated that brand leadership positively influence brand commitment and BCBs (namely helping behavior, brand enthusiasm and brand development). Hence, it is important to examine how different types of brand leadership (i.e. transactional and transformational) influence employees' brand commitment and BCBs.

Thus, managerial implications are also found explaining how managers could train $\mathrm{BCB}$ related skills of employees to get more brand related behaviors to deliver brand value propositions whilst brand knowledge is 
established. Connecting consumer responses to brand is supported by employee commitment towards the brand. Therefore, studies could further verify how BCB and brand commitment of employees are interrelated in different sectors including services.

Studies mentioned that employee brand love as an emotional response of the staff towards the employer brand and $\mathrm{BCB}$ could support for such extended emotional commitments. Internal brand practices are not sufficient to align the behavior of employee's brand. Theories of social identity, organizational identification and organizational commitment could motivate the employees to comply with the strategic interest of the Organization. Additionally, more engaged employees and more identified with the brand of the organizations, the greater the tendency to participate in the BCB. As suggested by Burmann and Zeplin (2005), the commitment of the brand and $\mathrm{BCB}$ are the key ingredients in the global management of brand identity base. Literature required that employees who are committed to the brand are being able to display favorable attitude and behavior toward the brand, thus increasing the satisfaction of the customer external (Burmann \& Zeplin, 2005). Employees in a spirit of high brand citizenship are willing to give 'everything' to achieve personal satisfaction and objectives of the organization. For example, these employees demonstrate high level of helping behavior and compliance with the values of brand, enthusiastic, demonstrate commitment to voluntary brand, seeking self-development in the brand's values and to communicate positive words about the brand (Burmann \& Zeplin, 2005). Such behavior also presents that employees are highly conscious, satisfied, committed and loyal to the brand (Punjaisri and Wilson, 2007). Therefore, employees who lack such features not only are dissatisfied and unfair to brand, but also possibly dilute the overall performance of the brand especially in the fulfillment of the promise of brand to external customers. Employees could act as agents of a brand as brands need people in value creation (Kahadawarachchi et.al., 2016).
Thus, BCB and its connected concepts should be carefully examined in managerial perspectives. For instance, studies found in financial services sector had discussed how to manage the BCB related skills of staff in relation to brand knowledge-related aspects since all those strategies are interconnected, and such overall strategies are very crucial in modern banking environment (Nayanajith \& Dissanayake, 2019; Nirmali et al., 2018).

While numerous studies have tried to examine the role of mediator of commitment of employees on the relationship between internal branding and the employees brand behaviors, there is still no consensus of the term 'brand's commitment'. Some scholars have conceptualized brand as a part of brand's commitment to workers (Punjaisri et al., 2009), while other researchers attitude dimension (Burmann et al., 2009). Supportively, Kimpakorn \& Lyon (2009), argue that the brand's commitment is a unique construction with a dimension or multiple dimensions. Although Burmann et al. (2009), attempted to identify the multiple dimensionality of the commitment (i.e., brand compliance, identification brand and internalization) in consistency with the researchers in organizational studies which argue that the commitment of the employees could be explained better as a multidimensional construct failed to demonstrate the multidimensionality of the brand's commitment. Because of the complexity and amplitude of the BCBs, it is postulated that they cannot easily connect employees brand to the organizations, based on a single dimension of the brand's commitment. Therefore, it is suggested that commitment of employees would explain better and tested as having three dimensions to know brand of compliancy, brand identification and internalization (Kimpakorn \& Lyon, 2009). These three dimensions of the brand's commitment is consistent with the Hierarchy of Employees Brand Engagement Model (HEBEM) suggested by Nelson (2005). In this study, brand commitment refers to the measurement of psychological fixation of employees to the brand, which affects their willingness to exert 
extra effort to achieve the objectives of the brand (Burmann \& Zeplin, 2005).

\section{CONCLUSION}

This paper mainly discussed the concept of $\mathrm{BCB}$ as a comprehensive review based on the related empirical evidences. Moreover, paper attempted to justify how $\mathrm{BCB}$ and related concepts and available interrelate in research domains. In brief, author attempted to connect the relationships found with $\mathrm{BCB}$ connected to brand knowledge and brand engagement as some of the main aspects within. In addition, paper highlights different contents of $\mathrm{BCB}$ based on the empirical evidences as it referred in many sectors whilst services are much highlighted. Additionally, paper portrayed the managerial significance of the $\mathrm{BCB}$ and internal branding strategies whilst some notions are emphasized on developing skills related to brand-connected behaviors. Alongside, author suggests future studies to further investigate the $\mathrm{BCB}$ with different concepts including mediating and moderating mechanisms in different sectors whilst services like retail, financial services, hotels, education and other sort of employee-centric industries are much highlighted.

\section{REFERENCE}

Aaker, D. A. (1996). Measuring brand equity across products and markets. California Management Review, 38(3).

Baumgarth, C., \& Schmidt, M. (2009). How Strong is the Business-to-Business Brand in the Workforce?-Model and Empirical Test of 'Internal Brand Equity in a Business-toBusiness Setting. Marketing-Impulse, working paper, (4).

Buckley, R., \& Caple, J. (1995). The Theory and Practice. Training.

Burmann C,Zeplin S.Riley. (2009). Key determinants of internal brand management sucess :an exploratory empercal analysis . Brand Management, 264-284.
Burmann, C. and Zeplin, S. (2005). Building brand commitment: A behavioral approach to internal brand management. Journal of Brand Management, Vol. 12 No. 4, pp. 279300.

de chernatony L Cottam S.Segal Horn S. (2009). "Communicating Servises Brands Values Internally ". Service Industries Journal, Vol 26 No 8.

Dissanayake D. M. R, Ismail N. \& Pahlevan Sharif, S (2017). Influence of Celebrity Worship Motives on Perceived Brand Evaluation of Endorsed-Brand, Proceeding of the International Conference on Advanced Marketing, Vol. 1, 1-9, DOI: https://doi.org/10.17501/icam.2017.1101

Ellickson, M. C., \& Logsdon, K. (2002). Determinants of job satisfaction of municipal government employees. Public Personnel Management, 31(3), 343-358

Gayan Nayanajith, D. A. \& Dissanayake, D. M. R. (2019). "E-Banking Adoption in the Context of Innovation and E-Service Quality: A Review on Concepts and Practices", Journal of Environmental Science, Computer Science and Engineering \& Technology, Vol.8 Issue:3, pp.208-221, https://doi.org/10.1108/0265232031045777 6.

Ind .N. (2001). Living the Brand . London : Kogan page.

Jayampathi, G.A.S., \& Dissanayake, D.M.R., (2018). Impact of Brand Citizenship Factors towards Sales Force Motivation: A Conceptual Review on Financial Leasing Service Sector of Sri Lanka. Singaporean Journal of Business Economics, and Management Studies (SJBEM), 6(09), 1-9.

Kahadawarachchi, L.K.K., Dissanayake, D.M.R. \& Maitra,R. (2016). Role of Relative-Agency of Consumers in Brand Building: Conceptual Review for Marketing Implications and Future Studies, Sri Lanka Journal of Marketing (SLJM), Vol 2, Issue 3, 35-58. 
Keller, L. K. (2010). Brand Strategic Management. Atiyeh Bathayi Tehran: SITEH Publication.

Kimpakorn, N. and Tocquer, G. (2009). Employees' commitment to brands in the service sector: Luxury hotel chains in Thailand. Journal of Brand Management, Vol. 16, No. 8, pp. 532-544.

King, C. and Grace, D. (2008). Internal branding: Exploring the employee's perspective. Journal of Brand Management, Vol. 15, No. 5, pp. 358-372.

Morhart, F. M., Herzog, W., \& Tomczak, T. (2009). Brand-specific leadership: Turning employees into brand champions. Journal of Marketing, 73(5), 122-142

Nirmali, K.A.A., Khathibi, A., \& Azam, S.M.F. (2018). Exploring Employees Brand Knowledge in Sri Lankan Banking Sector. European Journal of Social Sciences Studies, 3(1).

Punjaisri, K. and Wilson, A. (2007). The role of internal branding in the delivery of employee brand promise. Journal of Brand Management, Vol. 15, No. 1, pp. 57-70.

Solnet, D. (2006). Introducing employee social identification to customer satisfaction research.Managing Service Quality: An International Journal.

Thomson, K. De Chernatony, L. Arganbright, L. and Khan, S. (1999). The Buy-in Benchmark: How Staff Understanding and Commitment Impact Brand and Business Performance. Journal of Marketing Management, Vol. 15, No. 8, pp. 819- 835. 